\title{
REFLEXÕES SOBRE \\ O CONSUMO NA HIPERMODERNIDADE: - Diagnóstico de uma Sociedade Confessional
}

\section{Dennis Verbicaro}

Doutor em Direito do Consumidor pela Universidad de Salamanca (Espanha). Mestre em Direito do Consumidor pela Universidade Federal do Pará. Professor da Graduação e do Programa de Pós-Graduação Stricto Sensu da Universidade Federal do Pará - UFPA. Professor da Graduação e Especialização do Centro Universitário do Pará - Cesupa. Professor-visitante da Pós-Graduação Lato Sensu em Direito do Consumidor da Universidade Federal do Rio Grande do Sul - UFRGS. É Procurador do Estado do Pará e advogado.dennis@gavl.com.br

\section{Lays Soares dos Santos Rodrigues}

Mestranda do Programa de Pós-Graduação em Direito da Universidade Federal do Pará (PPGD-UFPA) e advogada. layssoares_@hotmail.com

\section{Resumo}

0 presente artigo propõe-se a analisar o panorama de transição da pós-modernidade para a denominada hipermodernidade e a consequente transformação do consumo na maior força propulsora da sociedade contemporânea, que resultou no agravamento da vulnerabilidade do consumidor. Nesse sentido, buscar-se-á compreender quais as causas que legitimam esse quadro e levam ao consumo desenfreado, com destaque para as perspectivas da autossatisfação hedonista e da diferenciação social. É à luz dessas diretrizes que 0 artigo, pelo método dedutivo e pesquisa bibliográfica nacional e estrangeira, buscará compreender a atual dinâmica da sociedade de consumo, bem como os desafios da tutela consumerista diante dessa nova realidade.

\section{Palavras-chave:}

Direito do Consumidor. Hipermodernidade. Hedonismo. Diferenciação social. Vulnerabilidade. 


\section{REFLECTIONS ON CONSUMPTION IN HYPERMODERNITY: the diagnósis of a confessional society}

\section{Abstract}

This article proposes to analyze the panorama of transition from postmodernity to the socalled hypermodernity and the consequent transformation of consumption into the major driving force of contemporary society, which has resulted in the aggravation of consumer vulnerability. In this sense, we will try to understand the causes that legitimize this situation and lead to unbridled consumption, with emphasis on the perspectives of hedonistic selfsatisfaction and social differentiation. It is in the light of these guidelines that the article, through the deductive method and national and foreign bibliographic research, will seek to understand the current dynamics of the consumer society, as well as the challenges of consumer protection in the face of this new reality.

\section{Keywords:}

Consumer Law. Hypermodernity. Hedonism. Social differentiation. Vulnerability.

Recebido em: 17/4/2017

Aceito em: 12/10/2017

\section{Sumário:}

1 Introdução. 2 Da pós-modernidade à hipermodernidade: a paradoxal hipersociedade dos dias atuais. 30 consumo entre autossatisfação hedonista e a diferenciação social. 4 Conclusão. 5 Referências. 


\section{INTRODUÇÃO}

A sociedade contemporânea tem vivenciado crescentes e intensas transformaçóes, nos mais variados aspectos, que impactam diretamente na forma como se desenvolvem as condiçóes de vida das pessoas, bem como suas relaçóes, interesses e valores.

Nesse contexto, a sociedade de consumo está diretamente relacionada com a pós-modernidade, integrando, pois, a própria essência desta. É forçoso admitir, porém, que muito embora a consolidaçáo desta sociedade já esteja completamente enraizada no nosso cotidiano, o que hoje se vivencia é muito mais que uma mera continuidade da era pós-moderna.

O intenso fluxo informacional, o ritmo frenético do cotidiano, a ampliação do alcance da influência midiática, e, principalmente, a valorização do consumo: todos esses foram fatores fundamentais na estruturação de um novo cenário, em que o consumo se elevou como a maior força propulsora dessa nova era, a qual podemos chamar de hipermodernidade.

A era hipermoderna é marcadamente paradoxal, na medida em que possibilitou a coexistência de valores completamente antagônicos. Essa conjuntura reflete diretamente no posicionamento do homem contemporâneo, que, diante de tantos avanços e da exigência de que se acompanhe todos eles sob pena de exclusão social, vê-se nulificado e inevitavelmente absorvido pela lógica predatória do mercado.

Assim, é importante que se busque compreender a forma pela qual essa nova realidade se estruturou, para que então se descubra a razão que levou o consumo a assumir um papel central na vida dos indivíduos, e, consequentemente, de ter elevado a vulnerabilidade do consumidor a um nível jamais antes vislumbrado.

Numa realidade em que todos os elementos sociais foram "hiperintensificados”, já não se fala mais em consumo, mas sim em um hiperconsumo que, para se manter, precisa de hiperconsumidores, convencidos de que a aquisiçáo dos bens e serviços divulgados pela indústria cultural de massa é uma verdadeira necessidade para se manter nessa sociedade líquida. 
Partindo dessas reflexôes, o presente artigo busca analisar, por intermédio de pesquisa teórica e com base em uma visão crítica, como se deu o advento de uma terceira etapa da modernidade e por que se fala em uma sociedade repleta de paradoxos; bem como compreender o impacto desses influxos na estruturação de uma nova relação do homem com o consumo, na medida em que este passa a assumir funçôes que vão muito além de uma perspectiva meramente utilitarista.

E, nesse contexto em que o consumo se tornou um fenômeno muito mais complexo do que parece, serão abordadas as novas acepçóes a ele atribuídas, na tentativa de encontrar respostas para um questionamento que sequer é cogitado pela maioria dos consumidores antes de tomar suas decisões: Por que se consome? Por uma questão de autossatisfação hedonista ou de diferenciação social?

É à luz dessas diretrizes que o artigo, pelo método dedutivo e pesquisa bibliográfica nacional e estrangeira, buscará compreender a atual dinâmica da sociedade de consumo, bem como os desafios da tutela consumerista diante dessa nova realidade, sendo certo que a adequada percepçáo acerca dos fatores que desencadeiam essa busca desenfreada pelo consumo e as consequências daí advindas são fundamentais para esse fim.

\section{DA PÓS-MODERNIDADE À HIPERMODERNIDADE: a Paradoxal Hipersociedade dos Dias Atuais}

Para a sociedade de consumo atual, o termo pós-modernidade já parece inapropriado para descrever todas as inovaçóes e peculiaridades verificadas no cotidiano. A intensa velocidade do fluxo informacional, a preocupação com o futuro, o consumo exacerbado, o poder das mídias sociais: todas essas são características indissociáveis do homem contemporâneo.

Segundo Lipovetsky (2004, p. 25), um termo mais consentâneo para designar a realidade atual seria hipermodernidade. Como corolário da terceira fase da modernidade, essa nova era é evidenciada por uma sociedade marcadamente fluida, líquida e essencialmente paradoxal. 
Nesse sentido, a valorização do presente e o individualismo característico da pós-modernidade continuam existindo, mas passam a conviver com uma postura mais responsável e mais preocupada com o futuro. E é nesse contexto de coexistência de valores antagônicos que surgem os paradoxos da hipermodernidade, conforme observa Lipovetsky (2004, p. 27):

Eis apenas uma amostra dos paradoxos que caracterizam a hipermodernidade: quanto mais avançam as condutas responsáveis, mais aumenta a irresponsabilidade. Os indivíduos hipermodernos são ao mesmo tempo mais informados e mais desestruturados, mais adultos e mais instáveis, menos ideológicos e mais tributários das modas, mais abertos e mais influenciáveis, mais críticos e mais superficiais, mais céticos e menos profundos.

Com efeito, ao analisarmos o panorama de transição da era clássica para a modernidade, é possível identificar uma tendência de emancipação com relação aos valores tradicionais da época. Ocorre que, paralelamente a essa inclinação liberatória, houve uma ampliação do poder estatal, o que fez com que aqueles anseios permanecessem, em grande parte, num plano sobretudo teórico, num processo de desencantamento com o mundo, em que se passou a ter a convicçáo de que as muitas promessas da modernidade não foram cumpridas.

Apenas com a pós-modernidade foi que essa ruptura, de fato, ocorreu, verificando-se, a partir de então, o delineamento da figura de um indivíduo mais voltado para o presente, menos subserviente e mais hedonista. Nesse contexto, o consumo de massa e os valores por ele difundidos podem ser apontados como fatores decisivos na passagem da modernidade à pós-modernidade, ocorrida na segunda metade do século 20 (LIPOVETSKY, 2004, p. 23).

Atualmente, embora os elementos da pós-modernidade não tenham simplesmente desaparecido, o que se percebe é que o surgimento de novos valores, preocupações e situaçóes fizeram com que o termo pós-moderno passasse a ser insuficiente para descrever essa sociedade de excesso em que vivemos.

Não houve, contudo, um rompimento com relação aos ideais pós-modernos, mas sim o estabelecimento de novas convicçóes e estilos de vida, que passaram a coexistir com os anteriores. É justamente nesse ponto de convergência que residem os paradoxos da sociedade hipermoderna: o espírito essencialmente libertário e 
hedonista dos tempos pós-modernos passa a ser latente, e não mais evidente, enquanto uma responsabilidade hesitante advém. Para Lipovestky, o "narciso", isto é, o homem dos dias de hoje, passa a vivenciar contradiçóes (2004, p. 27):

Narciso maduro? Mas se ele não pára de invadir os domínios da infância e da adolescência, como se se negasse a assumir a sua idade adulta! Narciso responsável? Pode-se realmente pensar isso quando os comportamentos irresponsáveis se multiplicam, quando as declaraçôes de intenção não se concretizam? O que dizer dessas empresas que falam em códigos de deontologia e que, ao mesmo tempo, demitem em massa porque antes maquiaram os livros contábeis; desses armadores que evocam a importância de respeitar o meio ambiente enquanto seus próprios navios efetuam descargas selvagens de poluentes; desses empreiteiros que exaltam a qualidade de suas construçôes muito embora elas desabem ao menor abalo sísmico; desses motoristas que dizem respeitar o código de trânsito e falam ao celular enquanto dirigem? Narciso eficiente? Que seja, mas ao custo de distúrbios psicossomáticos cada vez mais freqüentes, de depressôes e estafas flagrantes. Narciso gestor? É de se duvidar, quando se observa a espiral de endividamento das empresas. Narciso flexível? Mas se é a tensão nervosa que o caracteriza no âmbito social quando chega a hora de perder certos benefícios adquiridos!

\begin{abstract}
A hipermodernidade simboliza o surgimento de uma nova modernidade, como uma espécie de "aprimoramento" daquela vivenciada anteriormente, conforme assevera Lipovestky (2004, p. 56):

Tudo se passa como se tivéssemos ido da era do pós para a era do hiper. Nasce uma nova sociedade moderna. Trata-se não mais de sair do mundo da tradição para aceder à racionalidade moderna, e sim de modernizar a própria modernidade, racionalizar a racionalizaçáo (...).
\end{abstract}

Assim é que uma nova realidade se estrutura, sem, porém, abandonar completamente a anterior. Observa-se, então, uma mutação incompleta, posto que a etapa hipermoderna não se inicia a partir de uma tabula rasa, mas sim em um panorama repleto de vestígios do status quo ante, que ensejam os paradoxos (BAUMAN, 2010, p. 54). 
Como um dos principais aspectos da hipermodernidade, pode-se indicar a mudança do panorama social e da relação dos indivíduos com o presente. Esse presente já não é mais vivenciado de forma plena e despreocupada. A constante inquietação com o que o futuro reserva esvazia o otimismo do carpe diem e a confiança no porvir.

Manifestando-se como mais um dos paradoxos contemporâneos, a visão do futuro passa a estar associada à oportunidade de avanços e mudanças positivas, mas, ao mesmo tempo, anunciam-se ameaças de catástrofes ambientais, terrorismo e conflitos mundiais. Desse modo, o homem passa a conduzir o presente voltando-se para o futuro, com a adoçáo de uma postura mais previdente, quanto à subsistência das geraçôes ulteriores, passando-se a falar, inclusive, na ideia de um "pacto entre as geraçôes".

Destarte, a nova percepção do futuro é marcada pelo abandono das utopias coletivas, mas, ao mesmo tempo, observa-se a intensificação da adoção de condutas preventivas (LIPOVETSKY, 2004, p. 68-69):

A impotência para imaginar o futuro só aumenta em conjunto com a sobrepotência técnico-científica para transformar radicalmente o porvir: a febre da brevidade é apenas uma das facetas da civilização futurista hipermoderna. Enquanto o mercado estende sua "ditadura" do curto prazo, as preocupações relativas ao porvir planetário e aos riscos ambientais assumem posição primordial no debate coletivo. Ante as ameaças da poluição atmosférica, da mudança climática, da erosão da biodiversidade, da contaminação dos solos, afirmam-se as ideias de "desenvolvimento sustentável" e de ecologia industrial, com o encargo de transmitir um ambiente viável às gerações que nos sucederem. (...) Morrem as utopias coletivas, mas intensificam-se as atitudes pragmáticas de previsão e prevenção técnico-científicas.

Por outro lado, toda essa preocupação com o amanhã tem sido responsável pelo aumento expressivo dos distúrbios psicossomáticos, originados a partir de um sentimento generalizado de medo e vulnerabilidade. Medo de eventuais catástrofes, medo do desemprego, medo de doenças, medo de não atender aos padróes impostos. 
Evoluir a todo custo e a todo instante passa a ser uma obrigação do homem contemporâneo: o homem estagnado está fadado ao fracasso. Consequentemente, a insatisfação é permanente, e é a insatisfação que acaba sendo o combustível dessa sociedade marcada pela brevidade.

Não seria desarrazoado afirmar que a hipermodernidade instaurou uma espécie de "mal-estar difuso", em que os seres humanos renunciam às relações interpessoais autênticas em prol de um modelo artificial de felicidade, que se reveste de uma aparência de bem-estar, mas que, no seu íntimo, esconde sentimentos de frustração, raiva, medo, ansiedade.

Nesse contexto, o hiperconsumo pode ser apontado como a pedra angular do cenário hipermoderno. Todos os planos e aspectos da vida parecem ter sido dominados por essa lógica, em que a incessante aquisição de bens materiais passa a ser vista como uma maneira de os indivíduos compensarem suas carências e frustraçóes.

O hiperconsumidor procura a felicidade não mais no "ser", e sim no "ter", e a partir do momento em que felicidade é associada a fatores exclusivamente tangíveis, o seu locus passa a ser as vitrines das lojas. Cada elemento ali exposto é, então, vislumbrado como um refúgio em meio ao vazio em que a hipersociedade se vê mergulhada.

Assim é que a felicidade deixa de ser algo transcendental e passa a ser consumível. O prazer que o consumo proporciona transforma-se em sinônimo de felicidade, de modo que quanto mais prazer o ser humano é capaz de obter, mais "feliz" ele é. A parte se confunde com o todo, e o prazer, que antes era concebido apenas como um dos fatores propícios à felicidade, é elevado à categoria de verdadeiro arquétipo da felicidade.

Exsurge, então, um consumo emocional, caracterizado por uma infindável busca pelo bem-estar por meio daquilo que se compra. A partir do momento em que sentimentos tấo importantes são reduzidos a uma perspectiva tão simplista $\mathrm{e}$ frívola, as enfermidades típicas dos tempos contemporâneos vêm à tona, como a fragilidade dos laços afetivos, o abandono familiar, a solidão, a depressão, os transtornos bipolares e consumistas (CARVALHO; FERREIRA; SANTOS, 2016, p. 52). 
É imperioso reconhecer que vivemos numa sociedade doente, cujos indivíduos, deprimidos, em pânico, ou apenas ansiosos, sequer conseguem compreender a gravidade do seu diagnóstico, enquanto que outros, inclusive, já perderam a capacidade de irresignação, pois se acostumaram com a indolência e a terceirização de suas escolhas.

Nesse cenário de tantas desordens, o modelo ideal de felicidade constitui a referência absoluta da sociedade de consumo, e, para tanto, precisa ser mensurável por intermédio de objetos e signos de conforto, isto é, com base em critérios visíveis, suscetíveis de serem percebidos pelos outros (BAUDRILLARD, 2008, p. 50).

A felicidade não precisa mais ser sentida, e sim provada, ao mesmo tempo que a liberdade para assumir as verdadeiras preferências é balizada pelos padróes "mínimos" de validade, instituídos e reforçados pela indústria cultural de massa. Por conseguinte, o indivíduo tem receio de se relacionar e expor aquilo que verdadeiramente é, passando a se esconder em grupos virtuais voláteis e transitórios, em que ninguém é obrigado a dizer a verdade e todos fingem ter uma vida perfeita.

Nessa vida "perfeita" é proibido expor fracassos, até mesmo porque a autoestima pessoal depende da aprovação dos "estranhos". Há, pois, um interesse recíproco em rivalizar com o outro as conquistas e realizaçóes, jamais as frustraçôes.

O consumo exacerbado nunca fez tanto sentido como na sociedade hipermoderna, porquanto nela encontra o alicerce necessário para se intensificar cada vez mais, alimentado pela permanente insatisfação de seus membros. Esse comportamento é decorrência lógica das necessidades e padróes impostos a todo o momento pela indústria cultural de massa.

Com efeito, o consumo é parte fundamental do cotidiano humano, sendo possível afirmar que hoje todos ostentam a qualidade de consumidor. O consumo imiscuiu-se na rotina diária dos indivíduos, desde as necessidades mais básicas (utilitaristas) às mais supérfluas, passando todas a depender do consumo e o ato de consumir passa a se tornar um traço característico do ser humano, um atributo indissociável do sujeito. Nessa conjuntura, as linhas claras que separam o necessário do supérfluo passaram a ser tênues, de modo que já não é mais tão simples distinguir entre o que se compra em razáo do que se precisa ou do que se deseja. 
Em um passado náo tão remoto, os meios e as possibilidades de compra eram bem mais restritos, de sorte que quando se falava em compras, logo vinham à mente objetos e comodidades materiais. A materialidade era atributo do consumo, e o imaterial estava fora do alcance.

Hoje, porém, se vive o tempo da fluidez: a sociedade e seus valores abandonaram sua imanente solidez em prol de um dinamismo próprio das coisas líquidas. Esse movimento impactou os mais variados aspectos sociais, inclusive o consumo, que passou de sólido para líquido.

A era da liquidez, marcada pela falta de profundidade das relaçóes e fugacidade, criou o ambiente ideal para o surgimento de novas necessidades e possibilidades de consumo, de maneira que os próprios indivíduos vivenciam um processo de "comodificação", transformando-se em mercadorias, na medida em que passou a ser possível comprar não apenas utensílios, mas receitas de vida (BAUMAN, 2001, p. 95).

Os indivíduos, ávidos para atender aos padróes impostos e melhorar cada vez mais sua imagem, compram fórmulas para saber o modo ideal de ser, de se comportar e de viver, terceirizando suas escolhas. Dessa forma, a contratação de profissionais como coaches e personal stylists tornou-se corriqueira e, para muitos, necessária, uma vez que, diante de tantas opçóes de escolha e da ânsia de se alcançar determinado status, sem correr o risco de errar, muitos preferem buscar uma orientação supostamente profissional, pois o resultado dessa escolha poderá vir a ser determinante para o sucesso social.

Verifica-se, pois, uma manifesta padronização do consumo, cuja inobservância tende a fazer com que o indivíduo "desapareça”, sendo simplesmente ignorado pelos demais, justamente por não ter conseguido acompanhar a exigência predatória da moda e dos novos símbolos de consumo que surgem diariamente. Para ser "notado", ou para ter algum "valor social”, o indivíduo precisa consumir e, mais além, mostrar aos outros que não apenas consome, mas que o faz com rapidez, voracidade e sem nenhuma culpa. 
Diante da inegável primazia da lógica consumista, é forçoso questionar se todas as esferas da vida foram reduzidas ao ato de consumir. A despeito de todas as evidências que apontam nesse sentido, a resposta é que ainda existe um núcleo intangível de valores que, felizmente, resistem ao mundo do consumo.

A hipermodernidade não é sinônimo de niilismo moral. Muito pelo contrário, certos valores como o respeito e a tolerância se solidificaram, os direitos humanos são cada vez mais protegidos e a verdadeira afetividade é mais valorizada do que nunca. Devido à efemeridade ínsita à era do hiper, esse núcleo de valores passa a ser ainda mais sublime, sobretudo em um tempo marcado por tantas relaçóes superficiais e descartáveis.

Embora à primeira vista o que acaba de se afirmar possa parecer contrário ao que foi exposto até entáo, a verdade é que se trata de mais um dos paradoxos dessa hipersociedade em que vivemos.

\section{CONSUMO ENTRE AUTOSSATISFAÇÃO HEDONISTA E A DIFERENCIAÇÃO SOCIAL}

O consumo, em sua acepção mais pura, talvez seja tão antigo quanto a sociedade. Ao se conceber o consumo como a aquisiçáo de bens e serviços com vistas à satisfação das necessidades humanas, se chegará à conclusáo de que se trata de uma prática secular e inerente à vida em comunidade.

Não obstante, o sentido do consumo sofreu inegáveis transformaçóes nos últimos tempos, de modo que, entre as várias acepçôes que lhe podem ser atribuídas, a que prevalece na era do hiper é aquela que o eleva ao extremo. O significado contemporâneo do consumo é inédito e multifacetado, pois passou a englobar tantas possibilidades que, restringi-lo à satisfação das necessidades humanas passou a ser uma forma meramente rudimentar - e até mesmo inadequada - de descrever esse fenômeno.

O consumismo dos dias de hoje não mais se limita a satisfaçáo das necessidades, mas também e, principalmente, dos desejos: 
O consumismo de hoje, porém, não diz mais respeito à satisfação das necessidades - nem mesmo as mais sublimes, distantes (alguns diriam, não muito corretamente, "artificiais", "inventadas”, "derivativas”), necessidades de identificação ou a autossegurança quanto à "adequação". Já foi dito que o spiritus movens da atividade consumista não é mais o conjunto mensurável de necessidades articuladas, mas o desejo - entidade muito mais volátil e efêmera, evasiva e caprichosa, e essencialmente não referencial que "as necessidades", um motivo autogerado e autopropelido que não precisa de outra justificação ou "causa”. A despeito de suas sucessivas e sempre pouco duráveis reificaçóes, o desejo tem a si mesmo como objeto constante, e por essa razão está fadado a permanecer insaciável qualquer que seja a altura atingida pela pilha dos outros objetos (físicos ou psíquicos) que marcam seu passado (BAUMAN, 2001, p. 96-97).

A intrínseca volatilidade dos desejos vai ao encontro dos valores típicos da sociedade líquida, tornando-se o fator que propulsiona e alicerça a dependência consumista. A superficialidade hoje vivenciada faz com que os indivíduos vejam a satisfação dos seus desejos como uma forma de se libertar do inevitável vazio instaurado, mas o efeito é justamente o contrário: uma vez que os desejos são fluidos e transitórios, a plena satisfação não consegue ser alcançada, e então o ciclo recomeça, impelido pela esperança de que essa satisfação um dia ocorra.

Mais que um fator propulsor, a noção de desejo é responsável por equiparar o consumo a uma forma de expressão, em que os bens ostentados constituem símbolos aptos a moldar a identidade de cada um. Por conseguinte, as pessoas passam a desfrutar de uma liberdade na seleção da própria identidade e de mantê-la enquanto lhes for conveniente, bastando que se vá "às compras" (BAUMAN, 2001, p. 107).

Desse modo, vislumbra-se a consolidação de um consumo de signos, detentor de uma linguagem própria, necessária para que os indivíduos estabeleçam relaçóes entre si, uma vez que o homem se relaciona na medida em que consome. Os bens de consumo funcionam, nesse cenário, como um canal de comunicaçáo necessário entre as pessoas, apto a identificar afinidades porventura existentes, posto que a lógica predominante é a de que pessoas que consomem as mesmas coisas têm as mesmas predileçóes, e, portanto, pertencem à mesma "tribo". 
Nesse contexto em que o consumo se tornou algo tão complexo, devido às inúmeras acepçóes e peculiaridades que assumiu, questiona-se: Por que se consome? Considerando que hoje o consumo é voltado para a satisfação de desejos, e não mais somente de necessidades, o ser humano consome por uma questão de autossatisfação hedonista ou em virtude de uma necessidade de diferenciação e, consequente, aceitação social?

$\mathrm{Na}$ medida em que o consumo passa a desempenhar um papel até mesmo na formação da personalidade de cada um, tentar separar o que se consome, visando ao prazer, do que se consome por reconhecimento social, constitui um verdadeiro desafio. As respostas para tais questionamentos não são fáceis de serem obtidas, sobretudo diante da onipotência da lógica consumista, que, reforçada pela indústria cultural de massa, pretende se erigir como a solução para os problemas contemporâneos.

O fato de hoje existirem tantas razóes que justificam e incentivam o consumo faz com que qualquer explicação que pretenda reduzir o consumo a uma única causa esteja fadada ao fracasso, conforme observa Zygmunt Bauman (2001, p. 104):

Há, em suma, razões mais que suficientes para “ir às compras”. Qualquer explicação da obsessão de comprar que se reduza a uma causa única está arriscada a ser um erro. As interpretaçóes comuns do comprar compulsivo como manifestação da revolução pós-moderna dos valores, a tendência a representar o vício das compras como manifestação aberta de instintos materialistas e hedonistas adormecidos, ou com produto de uma "conspiração comercial" que é uma incitação artificial (e cheia de arte) à busca do prazer como propósito máximo da vida, capturam na melhor das hipóteses apenas parte da verdade. Outra parte, e necessário complemento de todas essas explicaçôes, é que a compulsão transformada em vício de comprar é uma luta morro acima contra a incerteza aguda e enervante e contra um sentimento de insegurança incômodo e estupidificante.

Desse modo, tão complexo quanto o consumo contemporâneo são as causas que o promovem. Há uma inegável inclinação emotiva e hedonista no consumo, que, conforme Lipovetsky, faz com que os indivíduos consumam, antes de tudo, 
mais para sentir prazer do que para rivalizar com os demais, buscando tornar sua vida mais "produtiva. " Nesta perspectiva, o próprio luxo estaria mais relacionado com a satisfação que proporciona do que com o status (LIPOVETSKY, 2004, p. 25-26).

De fato, hoje, mais do que nunca, percebe-se uma íntima relação entre o consumo e o hedonismo, na medida em que a felicidade é equiparada ao prazer, e o prazer ao consumo. Assim, numa realidade em que todos têm o dever de ser felizes, o consumo aparece como um meio supostamente eficaz para se alcançar essa finalidade. É por essa razão que hoje se consomem não apenas objetos, mas também experiências e sensaçóes.

Diante das frustraçóes e inquietaçóes do cotidiano, o consumo aparece como um refúgio, amparado na crença de que quanto mais se consome, mais próximo da felicidade se estará. E é nesse sentido que a perspectiva hedonista do consumo se fortalece e difunde a ideia de que o consumo pode ser uma forma de se atenuar as infelicidades e, ao mesmo tempo, de se recompensar os esforços individuais mediante o raciocínio "compro porque mereço".

Paralelamente a essa visão hedonista, há, no consumo, uma acepção social, evidenciada pela sua capacidade de comandar o processo de estratificação da sociedade. Assim, pode-se afirmar que há, ao lado do "consumo emocional", um "consumo social", porquanto os bens consumidos possuem o condão de determinar a posição do indivíduo na sociedade, ou mesmo de diferenciá-lo em relação aos demais.

A lógica social do consumo pode ser analisada a partir de dois aspectos fundamentais. Primeiramente, como processo de identificação e de comunicação, estruturado em um código constituído por práticas de consumo que equivalem a uma espécie de linguagem e de identidade pessoal, conforme abordado anteriormente. $\mathrm{O}$ segundo aspecto fundamental consiste exatamente na questão da diferenciação social, em que os bens se apresentam como verdadeiros valores estatutários no seio de uma hierarquia (BAUDRILLARD, 2008, p. 66).

${ }^{1}$ A ideia de produtividade estaria relacionada à incessante busca por novas experiências, ou seja, não se poderia desperdiçar nenhum momento de uma vida repleta de oportunidades de prazer e tantos desejos a realizar. Uma vida produtiva seria uma vida "bem vivida" pela realização dessa autossatisfação. 
$\mathrm{Na}$ sociedade de consumo, este representa uma força social, que impóe que todos sejam consumidores por vocação, caso pretendam ser membros legítimos daquela e náo correrem o risco de serem desprezados (BAUMAN, 2008, p. 76). É nesse cenário que se desenvolve a perspectiva do consumo como forma de diferenciação social.

Este panorama está intimamente relacionado com a consolidação do modelo de um consumo baseado em signos. $\mathrm{O}$ que se consome tem o poder não apenas de delinear a identidade, mas também de revelar a classe de cada um, e é justamente esse fato que acarreta a diferenciaçáo social, uma vez que nem todos têm acesso aos mesmos bens.

Com base nessa perspectiva, consome-se não pelos objetos em si, mas sim pela aptidáo que estes, em sentido amplo, possuem de se manifestarem como signos que distinguem o indivíduo e, consequentemente, o inserem em determinada camada social (BAUDRILLARD, 2008, p. 66).

Nesse contexto, cada status apresenta um conjunto mínimo de bens considerados necessários para que uma pessoa seja vista como pertencente ao respectivo grupo. Possuir esse conjunto de bens deixa de ser apenas uma questão de satisfação, mas também de autoafirmação social. Inicia-se, então, uma incessante busca pelo prestígio que esses bens oferecem, que, por sua vez, é reforçada pela indústria cultural:

A relação deve estabelecer-se, portanto, entre a diferenciação crescente dos produtos e a diferenciação crescente da procura social de prestígio. Ora, a primeira é limitada, mas não a segunda. Não existem limites para o homem enquanto ser social (...). É precisamente aí que residem o valor estratégico e a astúcia da publicidade: atingir cada qual em função dos outros, nas suas veleidades de prestígio social reificado. Nunca se dirige apenas ao homem isolado (...) (BAUDRILLARD, 2008, p. 72).

Assim é que o processo de aquisição de um bem é tomado por uma complexidade insólita, uma vez que passa a importar na adesão a valores aptos a identificar a qual grupo o indivíduo pertence. $\mathrm{O}$ consumidor, ciente de que caso não atenda aos padróes impostos poderá vir a ser excluído ou estigmatizado, torna-se refém do medo da inadequação. De outro lado, os mercados de consumo, ávidos por tirar 
vantagem desse medo, produzem os bens de consumo necessários para se alcançar o status desejado, que, por sua vez, é definido a partir das técnicas de manipulação da indústria cultural de massa. Trata-se, pois, de um ciclo sem-fim, movido pela ânsia da aprovação social prometida pelos bens.

Consequentemente, devido à hegemonia dos padrōes sociais estabelecidos, bem como da ligação profunda que então se estabelece entre os bens de consumo e o processo de estratificação social, algumas pessoas veem o consumo como uma forma de realização na escala social vertical (LIPOVESTKY, 2004, p. 71).

Não se pode esquecer, porém, que esse processo ocorre muitas vezes de maneira inconsciente, uma vez que o consumidor tende a vislumbrar suas escolhas como fruto de sua liberdade, e náo como algo voltado para se alcançar determinado status.

De todo modo, o que se percebe é que o consumismo se tornou onipresente e onipotente, produtor da maior força propulsora da sociedade contemporânea. Buscar justificar esse fenômeno com base em uma única causa seria o equivalente a menosprezar o seu poder, que provém exatamente das múltiplas razóes que levam a ele.

E é exatamente essa justificativa plural para o consumo que enseja uma reflexão mais profunda acerca do comprometimento da capacidade decisória do consumidor e a necessidade de revisão da estrutura normativa atualmente disponível para o controle do assédio de consumo e de muitas técnicas empresarias coercitivas, que vulneram, ainda mais, a já combalida liberdade de escolha do consumidor.

Vive-se naquilo que Debord chamou de "Mundo Invertido", em que o verdadeiro é apenas um momento do falso (DEBORD, 2007, p. 40), pois numa sociedade confessional como a atual, não basta apenas adquirir os mutantes símbolos de consumo da indústria cultural, mas revelar a "feliz" aquisição aos demais, preferencialmente nas redes socais e condicionar o bem-estar à quantidade de "amigos" virtuais que aprovaram aquele momento.

O consumo, portanto, para ter um valor intrínseco para o sujeito, seja por seu caráter hedonista de autossatisfação pessoal, seja como "remédio" para as doenças da alma pós-moderna, fonte de reconhecimento social, ou mesmo quando 
a justificativa para o consumo seja puramente utilitarista (adquirir algo de que se precisa) dever ser "espetacularizado", naquilo que Debord chama de afirmação da aparência em negação da própria vida (2007, p. 40).

Para Debord:

Cuando la necesidad es soñada socialmente, el sueño se hace necesário. El espectáculo es el mal sueño de la sociedad moderna encadenada, que no expresa en última instancia más que su deseo de dormir. El espectáculo vela ese sueño (2007, p. 44).

Em outras palavras, vive-se numa realidade em que o assédio de consumo "hipnotiza" os homens, deixando-os adormecidos para as relações pessoais autênticas, forjando momentos artificiais de uma felicidade ilusória, pautada na premissa de que o consumo é o termômetro do poder social. Quanto mais se consome, maior o status alcançado na sociedade pós-moderna.

Apesar do prestígio social, todavia, este consumidor está só e infeliz, mas sua alienação é tão grande que muito dificilmente alcança a percepção de que vive num mundo sombrio, impessoal e que resume a relevância do sujeito a sua capacidade econômica, apenas.

É inegável a total pertinência da definição de Vargas Llosa para a banalização da cultura pós-moderna:

A raiz do fenômeno está na cultura. Ou melhor, na banalização da cultura imperante, em que o valor supremo é agora divertir-se e divertir, acima de qualquer outra forma de conhecimento ou ideal. As pessoas abrem um jornal, vão ao cinema, ligam a tevê ou compram um livro para se entreter, no sentido mais ligeiro das palavras, não para materializar o cérebro com preocupaçóes, problemas, dúvidas. Só para distrair-se, esquecer-se das coisas sérias, profundas e inquietantes e difíceis, e entregar-se a um devaneio ligeiro, ameno, superficial, alegre e sinceramente estúpido (2013, p. 123-124).

O consumo, portanto, tornou-se esse grande refúgio em homenagem ao ócio, ao prazer e à realização social, pois quanto mais distraído de suas responsabilidades diárias e pesados compromissos familiares e profissionais, maior será a propensão 
ao consumo e maior será a vulnerabilidade do consumidor assediado, pois verá no ato de consumir a expressão legítima de uma fuga à dura realidade dos papéis sociais que se vê obrigado a seguir.

A procura frenética pelos bens de consumo é a busca, na verdade, por uma pseudoliberdade, que mascara uma real infelicidade do indivíduo e seu crescente mal-estar pessoal e social.

Nesse sentido:

O caráter sistêmico da crise que atravessamos é, portanto, formado por essa dupla excesso/mal-estar. As estratégias positivas de transformação devem então resolver a questão da articulação entre a "simplicidade", como aceitação dos limites, e o "melhor-estar", dando forte ênfase à palavra "estar" em "melhor-estar". Visto que, muitas vezes, aqueles chamados estados de "bem-estar" eram na realidade estados de "muito ter" (MORIN; VIVERET, 2013, p. 40).

Sugere-se, portanto, uma revolução social em busca de uma "sobriedade feliz", que permita alcançar um ponto de equilíbrio entre o "ter", aqui admitido apenas em sua vocação utilitarista (satisfação das necessidades básicas) com o "ser", permitindo que o sujeito escape de um subdesenvolvimento ético, afetivo e espiritual, preservando os bens comuns à humanidade (MORIN; VIVERET, 2013, p. 41-42).

É preciso romper com a dependência ao consumo como uma espécie de vício que desumaniza o sujeito, permitindo-lhe reencontrar sua estabilidade emocional e social, o que perpassa pela educação e conscientização em prol de uma maior responsabilidade decisória na hora de conter impulsos e escolher produtos e serviços racionalmente.

Comprar em razão de uma necessidade utilitarista significa vincular a real funcionalidade do bem a uma expectativa legítima do consumidor, ou seja, a aquisição dos bens de consumo atenderá a requisitos mínimos de prestabilidade e servibilidade. 
Não se pode confundir essa necessidade utilitarista autêntica com outras necessidades forjadas pelo mercado, a saber: necessidade de afiliação (estar na companhia de outras pessoas), necessidade de poder (controlar o próprio ambiente) e necessidade de singularidade (afirmar a identidade individual) (SOLOMON, 2016, p. 20-21).

É preciso difundir a ideia de que a autoestima do indivíduo não está no seu poder de compra, ou na submissão aos apelos publicitários do mercado e que uma decisão estritamente utilitarista quanto as suas necessidades de consumo não o excluirá da vida social, nem será motivo de constrangimento e depreciação financeira.

Ao contrário, revelará que ainda há espaço para uma vontade livre e espontânea do consumidor, a despeito da coação econômica do mercado e do comprometimento da subjetividade individual pelo assédio de consumo.

E será justamente essa vontade livre, consciente e responsável que terá o poder de reposicionar a autoestima cívica do consumidor, agora compreendido como cidadão, num patamar político mais elevado, permitindo-lhe influir (e acreditar no poder transformador de sua influência) no processo deliberativo para o aperfeiçoamento das normas de consumo, visando à revisão dos parâmetros éticos de atuação dos agentes econômicos, melhor corrigindo as distorçóes apelativas de um modelo predatório pautado no consumo compulsivo.

\section{CONCLUSÃO}

Os imensuráveis avanços trazidos pela globalização vieram acompanhados de uma profunda transformação na sociedade. No panorama pós-moderno, houve a edificação de uma sociedade de consumidores, em que o consumismo passou a representar uma inafastável premissa para a aceitação e reconhecimento sociais.

Entre a era moderna e a pós-moderna ocorreu uma verdadeira ruptura paradigmática, caracterizada pelo abandono de todos os freios institucionais que impediam a emancipação individual. O consumo, que até então se limitava à classe burguesa, tornou-se acessível às massas, resultando na edificação de uma "comunidade de consumidores" e na consequente transformação do homo faber - famosa 
expressão concebida por Hannah Arendt para designar o homem típico da era moderna, que se dedicava exclusivamente à produção - para o homo economicus, que se volta não só para a produção, como também para o consumo.

Não obstante, o ritmo frenético da era contemporânea situou a pós-modernidade no passado, náo devido à ocorrência de uma nova ruptura, mas sim no sentido de indicar que as transformaçôes até então vivenciadas foram elevadas a um nível hiperbólico, ensejando o surgimento de uma terceira fase da modernidade: a hipermodernidade.

Na sociedade hipermoderna, todas as mudanças trazidas pela pós-modernidade foram potencializadas, o que fez com que tudo adquirisse um novo sentido. Assim, todas aquelas transformaçóes pós-modernas passam a conviver com outras perspectivas e valores, numa ótica paradoxal de valores invertidos, antagônicos e essencialmente fluidos.

Essa modernidade líquida e paradoxal tem um ritmo próprio e intenso, e, ao mesmo tempo, impossível de ser acompanhado. Esse descompasso instaurou um verdadeiro vazio no homem, criando um ambiente propício para que o consumo se estabelecesse como uma forma supostamente eficaz de suprir as frustraçóes e angústias.

Trata-se, na realidade, de uma satisfação que jamais será atingida e é justamente esse o objetivo. A indústria cultural de massa, por intermédio de suas técnicas de manipulação, cria e forja necessidades a cada instante e os consumidores, ávidos por preencher o vazio constante, sucumbem às promessas de uma felicidade descartável.

O que torna esse cenário mais preocupante é que mesmo aqueles indivíduos que não cedem às promessas ilusórias do "consumo emocional” também são reféns do fenômeno, uma vez que, nos dias atuais, exercer o papel de consumidor náo é mais uma simples opção, mas sim uma obrigação imposta, ainda que de forma implícita, pelos ditames desse estilo de vida que desaprova toda e qualquer opção cultural alternativa. 
O hiperconsumo tornou os indivíduos reféns de sua lógica predatória, na medida em que desconhece diferenças de idade, gênero ou classe social: todos estão sujeitos às mesmas exigências para fazerem parte dessa sociedade. $\mathrm{O}$ acesso aos bens e mercadorias já náo é mais sinônimo apenas de riqueza, mas também da felicidade esperada na cultura ocidental.

O fenômeno hiperconsumista é multifacetado e onipresente. Já não se sabe mais distinguir com clareza as esferas do consumível e do não consumível, uma vez que até mesmo o imaterial é permeado por essa mentalidade. De outro lado, as causas que levam os indivíduos a consumir são as mais variadas possíveis: busca por autoafirmação social, procura pelo prazer, busca pela sua própria identidade e por um sentimento de pertencimento. É essa múltipla acepção que fez do consumo um fenômeno complexo como nunca, capaz de dominar todas as esferas da vida do homem.

Cada bem consumido corresponde não mais apenas a uma dada utilidade, mas sim à adesão de determinados valores, de sorte que todas as escolhas passam a ser condicionadas socialmente, e o consumidor cada vez mais vulnerável.

Há, pois, uma "mercantilização da vida", e o mais alarmante não é a expansão da lógica consumista em si, mas sim a volatilização dos indivíduos, a fragilização de sua personalidade e a desestabilização emocional.

Apesar de todas as críticas feitas ao consumo, a verdade é que não há um contramodelo crível, e nem se pretende defender o contrário. Deve-se, porém, atentar para o fato de que o principal player desse cenário é o que mais está sendo prejudicado e absorvido pela lógica das frivolidades.

Nesse panorama essencialmente paradoxal, exsurgem os desafios contemporâneos à tutela consumerista, que precisa, mais do que nunca, se adaptar a essa nova realidade, conscientizando o consumidor do seu papel e possibilitando a recuperação da sua autoestima cívica, não apenas na esfera nacional, mas, sobretudo, no panorama internacional, uma vez que o consumo não conhece fronteiras. 


\section{REFERÊNCIAS}

BAUDRILLARD, Jean. A sociedade de consumo. Lisboa: Edições 70, 2008.

BAUMAN, Zygmunt. A ética é possivel num mundo de consumidores? Rio de Janeiro: Zahar, 2011.

Modernidade líquida. Rio de Janeiro: Zahar, 2001.

. Vida a crédito. Rio de Janeiro: Zahar, 2010.

. Vida para consumo: a transformação das pessoas em mercadoria. Rio de Janeiro:

Zahar, 2008.

CARVALHO, Diógenes Faria de; FERREIRA, Vitor Hugo do Amaral; SANTOS, Nivaldo dos (Org.). Sociedade de consumo: pesquisas em direito do consumidor (volume 2). Goiânia: Espaço Acadêmico, 2016.

DEBORD, Guy. La sociedade del espetáculo. Valencia: Editions Gallimard, 2007.

LIPOVETSKY, Gilles. Os tempos hipermodernos. São Paulo: Barcarolla, 2004.

MARQUES, Cláudia Lima. A proteção dos consumidores em um mundo globalizado: Studium Generale sobre o consumidor como Homo Novus. Revista de Direito do Consumidor, São Paulo, ano 22, vol. 85, jan./fev. 2013.

MORIN, Edgar; VIVERET, Patrick. Como viver em tempo de crise? Rio de Janeiro: Bertrand Brasil, 2013.

SOLOMON, Michael. O comportamento do consumidor: comprando, possuindo e sendo. Porto Alegre: Bookman, 2016.

VARGAS LLOSA, Mário. A civilização do espetáculo. Rio de Janeiro: Objetiva, 2013. 